\title{
THE ISOLATION AND IDENTIFICATION OF BACTEROIDES SPP. FROM THE NORMAL HUMAN FAECAL FLORA
}

\author{
B. I. DUERDEN \\ Department of Medical Microbiology, University of Sheffield Medical School, \\ Beech Hill Road, Sheffield S10 2RX
}

GRAM-NEGA TIVE anaerobic bacilli are a major component of the normal flora of human faeces. In quantitative studies, Bacteroides spp. have been isolated in counts of $10^{11}$ organisms/g of faeces (Hill et al., 1971; Finegold, Attebury and Sutter, 1974; Finegold, 1977). Drasar (1974) isolated Bacteroides in greater numbers from subjects from developed countries whereas gram-positive anaerobes were predominant in the faeces of subjects from developing countries.

Investigators who have identified faecal Bacteroides have found that the $B$. fragilis group are the dominant species. A previous taxonomic scheme (Holdeman and Moore, 1974a) assigned all the bile- and penicillin-resistant faecal strains to the single species $B$. fragilis, with five subspecies; when detailed identification was undertaken the commonest faecal subspecies were ss. vulgatus and ss. thetaiotaomicron (Werner, 1974; Moore and Holdeman, 1975; Finegold et al., 1975). However, DNA-homology studies have shown that each subspecies is unique and should be assigned species status (Cato and Johnson, 1976) and several new species have been described to accommodate strains with different properties within the $B$. fragilis group (Holdeman and Moore, 1974b; Werner, Rintelen and Kunstek-Santos, 1975). Many other Bacteroides and Fusobacterium spp. have been found inconsistently in small numbers in faeces. This may reflect the problems of isolation, identification and classification of these organisms. B. asaccharolyticus (B. melaninogenicus ss. asaccharolyticus; Finegold and Barnes, 1977) has been isolated regularly from faeces (Werner, Pulverer and Reichertz, 1971) but in much smaller numbers than the $B$. fragilis group.

The present study was undertaken to assess the contribution of the different species and subspecies of Bacteroides to the normal faecal flora as part of the evaluation of a scheme for the identification of gram-negative anaerobic bacilli by conventional bacteriological tests (Duerden et al., 1980).

\section{MATERIALS AND METHODS}

Two hundred strains isolated from 20 specimens of normal human faeces were studied. Anaerobic incubation. The anaerobic procedure of Collee et al. (1972) was followed in all 
essential aspects; incubation was at $37^{\circ} \mathrm{C}$ in an atmosphere of $\mathrm{H}_{2} 90 \%$ and $\mathrm{CO}_{2} 10 \%$ (BOC Ltd Special Gases, Deer Park Road, London SW19 3VF). A slope of Simmons citrate medium seeded with Pseudomonas aeruginosa was included in each jar as a control.

Specimens. Fresh specimens (c. $5 \mathrm{~g})$ of faeces from 20 normal healthy adults were collected in $6 \mathrm{ml}$ of VMG II transport medium (Möller, 1966) in small screw-capped vials. The subjects were students, professional and technical colleagues and nurses undergoing routine screening for faecal pathogens. None had any gastro-intestinal disorder and none was receiving antibiotic therapy. The specimens were processed on the day that they were collected.

Isolation of Bacteroides. The specimens were dispersed in the transport medium by vortex mixing (Rotamixer, Hook and Tucker Instruments Ltd, Vulcan Way, New Addington, Croydon CR0 9UG) for $3 \mathrm{~min}$. One loopful $(0.01 \mathrm{ml})$ of the suspension was plated on a pre-reduced medium derived from the BM medium of Nash (see Williams et al., 1975) and made selective for Bacteroides by the addition of kanamycin $75 \mu \mathrm{g} / \mathrm{ml}$ and vancomycin $2.5 \mu \mathrm{g} / \mathrm{ml}$ (Holbrook, Ogston and Ross, 1978). Similarly, one loopful of a 100 -fold dilution of the suspension in (cooled) pre-steamed nutrient broth was streaked on a second plate of the selective medium. The plates were examined after incubation for $48 \mathrm{~h}$. All colony types were noted and five representative colonies were subcultured on to fresh BM agar without antibiotics. After re-incubation for a further $48 \mathrm{~h}$, additional colony types were noted and another five representative colonies were subcultured. A total of 10 isolates were studied from each subject; the colony types were selected in approximate proportion to their comparative numbers on the primary isolation plates. The isolates were suspended for freezing in Nutrient Broth No. 2 (Oxoid) with inactivated Horse Serum (Wellcome) $10 \%$ and glucose $1 \%$ and held at $-70^{\circ} \mathrm{C}$ in a liquidnitrogen container.

Identification of isolates. The strains were identified by the combined set of cultural, biochemical, tolerance and antibiotic-disk resistance tests described by Duerden et al. (1976, 1980). The tests were: colony morphology after anaerobic incubation for $48 \mathrm{~h}$ on blood agar; cell morphology in gram-stained smears from 48-h cultures on blood agar and in BM broth with cooked-meat particles (see Deacon, Duerden and Holbrook, 1978); pigment production on BM agar; haemolysis on human-blood agar; motility in BM broth; antibiotic-disk resistance tests with separate disks containing neomycin $1000 \mu \mathrm{g}$, kanamycin $1000 \mu \mathrm{g}$, penicillin 2 units or rifampicin $15 \mu \mathrm{g}$; tolerance tests with taurocholate, deoxycholate, Victoria blue $4 \mathrm{R}$ and ethyl violet; biochemical tests for the production of indole, digestion of gelatin, and hydrolysis of aesculin; fermention tests with glucose, rhamnose, trehalose, mannitol and xylose.

\section{RESULTS}

Complete sets of results were obtained from 197 isolates of gram-negative, non-sporing, non-motile, obligately anaerobic bacilli; three isolates proved to be gram-positive bacilli and were excluded from analysis. One hundred and eighty isolates representing 11 recognised species and subspecies of Bacteroides were identified and the numbers of isolates allocated to each species are shown in table I: 165 isolates were allocated to the $B$. fragilis group; eight asaccharolytic isolates produced black or brown pigmented colonies on BM agar and were identified as $B$. asaccharolyticus; one pigmented strain was $B$. melaninogenicus ss. intermedius and two were ss. melaninogenicus; four isolates were B. ruminicola and 13 isolates were non-pigmented and non-saccharolytic; four fermentative isolates could not be allocated to a recognised species.

\section{B. fragilis group}

The 165 isolates were non-pigmented, resistant to kanamycin, sensitive to 
TABLE I

Identification of 197 faecal isolates from 20 subjects

\begin{tabular}{lc}
\hline \multicolumn{1}{c}{ Species } & $\begin{array}{c}\text { Number of isolates } \\
\text { (and group total) }\end{array}$ \\
\hline B. fragilis group & $(165)$ \\
B. fragilis & 15 \\
B. vulgatus & 37 \\
B. distasonis & 30 \\
B. thetaiotaomicron & 36 \\
B. uniformis & 8 \\
B. variabilis/eggerthii & 24 \\
B. splanchnicus & 15 \\
B. melaninogenicus/oralis group & $(7)$ \\
B. melaninogenicus ss. melaninogenicus & 2 \\
B. ruminicola $\quad$ ss. intermedius & 1 \\
Asaccharolytic group & 4 \\
B. asaccharolyticus & $(21)$ \\
Non-pigmented non-saccharolytic spp. & 8 \\
Bacteroides spp. (unidentified) & 13 \\
& $(4)$ \\
\hline & TOTAL
\end{tabular}

rifampicin and fermented glucose; most were resistant to neomycin and penicillin, and tolerant of taurocholate and Victoria blue 4R. Seven subgroups were recognised within the $B$. fragilis group and most isolates gave patterns of results that were generally typical of one or other subgroup. The $15 \mathrm{~B}$. fragilis isolates were divided into two sets by the results of the gelatinase test: nine strains digested the charcoal-gelatin disk after incubation for 10-14 days and six did not. Four isolates gave atypical results: three did not ferment xylose, one was inhibited by taurocholate and one by Victoria blue $4 \mathrm{R}$ and taurocholate. The $37 \mathrm{~B}$. vulgatus isolates included 23 isolates that were tolerant of ethyl violet and 13 isolates that did not hydrolyse aesculin. The results obtained with the $30 \mathrm{~B}$. distasonis and $36 \mathrm{~B}$. thetaiotaomicron isolates were a little more varied. All were generally typical of the species but $15 \mathrm{~B}$. distasonis isolates and $12 \mathrm{~B}$. thetaiotaomicron isolates gave atypical results in resistance tests with neomycin or penicillin or in tolerance tests with taurocholate, Victoria blue $4 \mathrm{R}$ or ethyl violet; one $B$. distasonis isolate did not ferment xylose and rhamnose, and one $B$. thetaiotaomicron isolate did not ferment xylose. Similarly, one isolate of $B$. uniformis was inhibited by taurocholate and three by Victoria blue 4R, and four isolates did not ferment xylose. B. variabilis and B. eggerthii could not be separated in this study because the only significant difference between them in conventional tests is the fermentation of sucrose by $B$. variabilis and this test was not performed routinely at this stage of the investigations. With that exception, the results obtained with 24 isolates were typical of either species. The $15 \mathrm{~B}$. splanchnicus isolates produced indole, hydrolysed aesculin and fermented only glucose and, with two exceptions, xylose. Seven isolates gave atypical results in tolerance tests with taurocholate and Victoria blue 4R. 


\section{B. melaninogenicus/oralis group}

Only seven faecal isolates were identified as members of the $B$. melaninogenicus/oralis group. There were three pigmented strains of $B$. melaninogenicus that gave patterns of results typical of the species; the four non-pigmented isolates were $B$. ruminicola and were resistant to penicillin.

\section{Asaccharolytic group}

The 21 asaccharolytic isolates included eight pigmented isolates of $B$. asaccharolyticus that gave patterns of results typical of the species; four were resistant to the neomycin 1000- $\mu \mathrm{g}$ disk. The non-pigmented non-saccharolytic isolates were a heterogeneous group. Ten isolates that gave similar results to the $B$. asaccharolyticus strains were provisionally allocated to the species $B$. putredinis.

The three remaining non-saccharolytic isolates and four fermentative isolates could not be identified by the set of tests used in this investigation.

\section{Identification of isolates from individual subjects}

When identical isolates from one subject were treated as a single strain, 124 strains were isolated from the 20 subjects and the identity of these strains is shown in table II. The distribution of species amongst the 20 subjects is shown in table III. The mean number of strains obtained from each subject was $6 \cdot 1$ (range 4-9). A variety of strains was isolated from most subjects and the

TABLE II

Strains of Bacteroides spp. isolated from 20 subjects

\begin{tabular}{|c|c|}
\hline Species & $\begin{array}{l}\text { Number of strains } \\
\text { isolated } \\
\text { (and group total) }\end{array}$ \\
\hline $\begin{array}{l}\text { B. fragilis group } \\
\text { B. fraglilis } \\
\text { B. vulgatus } \\
\text { B. distasonis } \\
\text { B. thetaiotaomicron } \\
\text { B. uniformis } \\
\text { B. variabilis/eggerthii } \\
\text { B. splanchnicus }\end{array}$ & $\begin{array}{r}(99) \\
11 \\
20 \\
17 \\
18 \\
7 \\
18 \\
8\end{array}$ \\
\hline 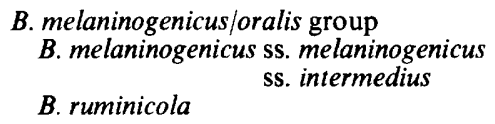 & $\begin{array}{c}(5) \\
1 \\
1 \\
3\end{array}$ \\
\hline $\begin{array}{l}\text { Asaccharolytic group } \\
\text { B. asaccharolyticus } \\
\text { Non-pigmented non-saccharolytic spp. }\end{array}$ & $\begin{array}{c}(17) \\
8 \\
9\end{array}$ \\
\hline Bacteroides spp. (unidentified) & (3) \\
\hline TOTAL & 124 \\
\hline
\end{tabular}




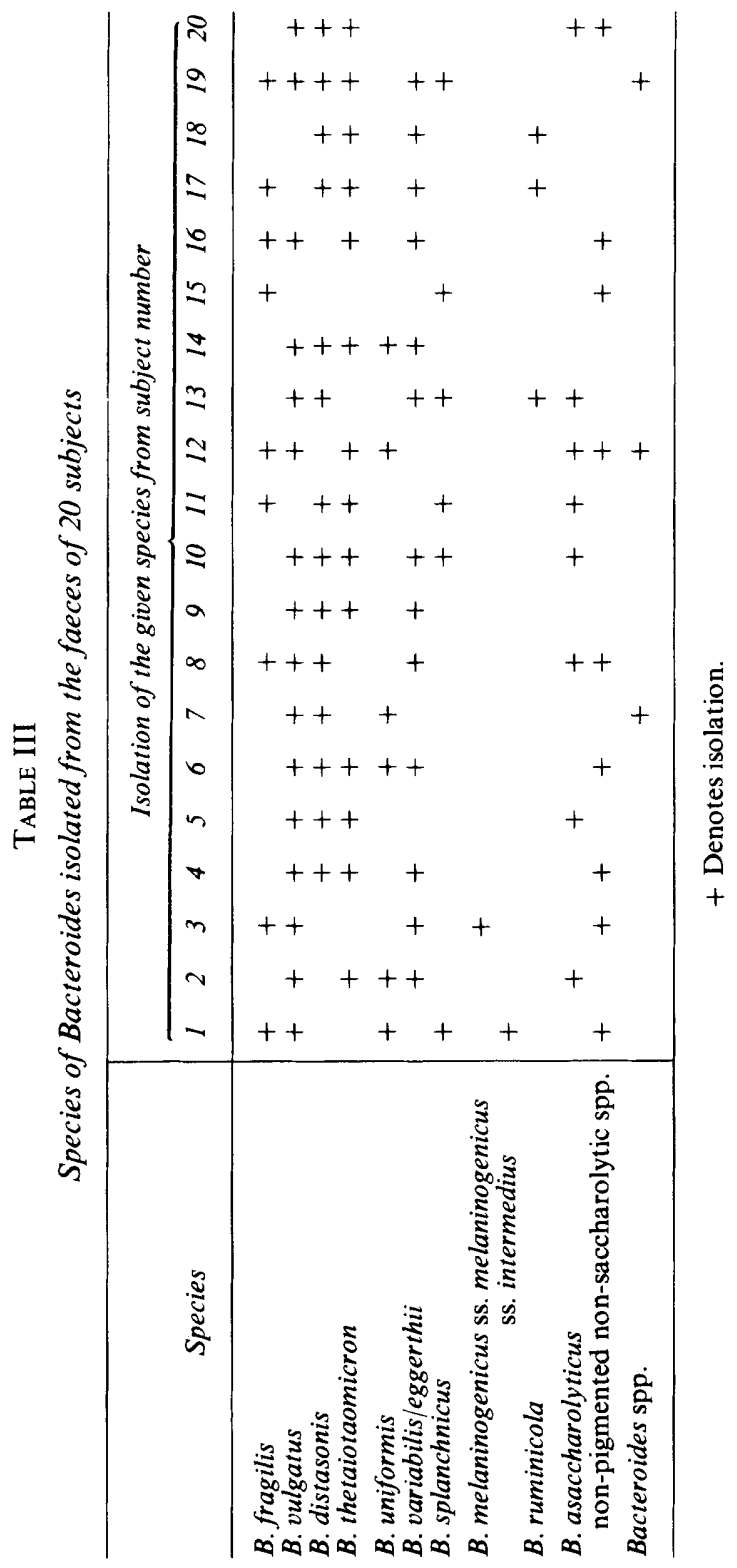


overall distribution of species was not distorted by the presence of large blocks of identical isolates from single subjects.

\section{Colony and cell morphology}

The mean number of colony types obtained from each subject was $4 \cdot 2$ (range 3-5) but the different subgroups could not be distinguished by colony appearance except for the pigmented strains and the non-pigmented non-saccharolytic strains that produced very small colonies. In the B. fragilis group, all isolates produced similar grey colonies that varied only in size on primary isolation. These differences were generally lost on subculture and were not typical of particular species; in individual subjects, isolates from different sizes of colonies gave the same results and isolates from apparently identical colonies gave different results.

Bacterial cell morphology had no discriminatory value in the $B$. fragilis group and varied with the culture medium. The appearance of isolates varied from fairly regular bacilli with rounded ends to highly pleomorphic organisms with mixtures of coccobacilli, bacilli and some bizarre, swollen forms. However, the $B$. melaninogenicus and $B$. asaccharolyticus isolates were predominantly coccobacillary and the non-pigmented non-saccharolytic strains were generally slender, regular, pale-staining bacilli.

\section{DISCUSSION}

The methods used for the isolation of Bacteroides from faeces in the present study had proved to be reliable when previously evaluated by colleagues. An anaerobic cabinet (Aranki et al., 1969; Aranki and Freter, 1972) was not used because Watt, Collee and Brown (1974) had shown that manipulation in a cabinet had no advantage for the recovery of anaerobes from faeces over prompt conventional handling at the bench with a well-controlled and standardised jar technique and freshly prepared or pre-reduced media. Rosenblatt, Fallon and Finegold (1973) and Starr (1974) also found that roll tubes (Hungate, 1950) had no advantage over conventional bench methods.

A selective medium was essential for the recovery of gram-negative anaerobic bacilli from the mixed faecal flora. Loesche, Hockett and Syed (1971) found kanamycin helpful in the isolation of B. melaninogenicus from dental plaque and Finegold, Sugihara and Sutter (1971) recommended that kanamycin and vancomycin be used for the selection of Bacteroides. The solid medium derived from the BM medium of Nash (see Williams et al., 1975) and containing kanamycin and vancomycin was recommended by Holbrook et al. (1978) for the isolation of B. melaninogenicus and other Bacteroides spp. from dental plaque; these authors also found that the use of VMG II transport medium (Möller, 1966) gave isolation rates of B. melaninogenicus as good as those from direct plating of specimens of plaque.

A very heavy growth of Bacteroides spp. was obtained from each specimen of faeces examined. This correlates with the viable counts of $c .10^{11}$ Bacteroi- 
des/g of faeces found in quantitative studies (Drasar, 1967; Hill et al., 1971; Finegold et al., 1974). Most of the isolates $(84 \%)$ ) belonged to the $B$. fragilis group that has been recognised generally as the predominant group of Bacteroides spp. in the normal flora of the lower gastro-intestinal tract. The commonest species isolated were $B$. vulgatus and $B$. thetaiotaomicron, which comprised $22 \%$ of the $B$. fragilis-group isolates each, B. distasonis $(18 \%)$ and the $B$. eggerthii/variabilis complex $(14 \%)$. B fragilis is the type-species of the $B$. fragilis group and is the most common species isolated from clinical infections (Werner and Pulverer, 1971; Werner, 1974; Holland, Hill and Altemeier, 1977; Duerden, unpublished) but only $9 \%$ of the $B$. fragilis-group isolates identified in the present study were $B$. fragilis. These results are similar to those of Werner (1974), Moore and Holdeman (1975) and Finegold et al. (1975) who also found that $B$. vulgatus and $B$. thetaiotaomicron were the commonest species isolated from faeces and that $B$. fragilis was found in smaller numbers. The occurrence of the different species in the present investigation was not distorted by large numbers of isolates of the most common species from only a few subjects; $B$. vulgatus was isolated from $80 \%$ of subjects, $B$. thetaiotaomicron and $B$. distasonis from $70 \%$ each and the $B$. eggerthii/variabilis complex from $65 \%$, whereas $B$. fragilis was isolated from only $45 \%$ of subjects.

Asaccharolytic gram-negative anaerobic bacilli were isolated from 14 $(70 \%)$ subjects. The 21 isolates represented 17 separate strains and included eight strains of $B$. asaccharolyticus, which has been isolated regularly from faeces by other workers but in much smaller numbers than the $B$. fragilis group (Werner et al., 1971). It is unlikely that B. asaccharolyticus would have escaped detection in the present study unless they were present in very small numbers; strains of $B$. asaccharolyticus grew well under the selective conditions used and the characteristic pigmented colonies were easily seen amongst the more numerous $B$. fragilis-group colonies. The identification of non-pigmented non-saccharolytic strains is difficult; this group of Bacteroides is not well represented in the identification scheme used (Duerden et al., 1980) and few type or reference strains are available. Some strains were distinguished from $B$. asaccharolyticus only by their failure to produce pigment and these strains were tentatively identified as $B$. putredinis by reference to the scheme given in the VPI Anaerobe Laboratory Manual (Holdeman, Cato and Moore, 1977).

Only seven isolates representing five separate strains of species in the $B$. melaninogenicus/oralis group were identified in the present study. Similarly, fusobacteria were not detected in the specimens of faeces. This indicates that the B. melaninogenicus/oralis group and the fusobacteria are not part of the normal flora of the lower gastro-intestinal tract and faeces. Alternatively, these species could have been inhibited by the selective medium if this was specifically formulated for the selection of the $B$. fragilis group, but large numbers of the $B$. melaninogenicus/oralis group were isolated on the same selective medium under the same conditions from the vagina and the mouth, and fusobacteria were isolated from the mouth (Duerden, $1980 a$ and $b$ ).

All except 17 isolates representing 12 strains were identified by the scheme 
based upon the short combined set of tolerance tests, antibiotic-disk resistance tests and conventional biochemical tests (Duerden et al., 1976, 1980). Ten more isolates representing six strains were provisionally identified by the same tests but with reference to the VPI Anaerobe Laboratory Manual (Holdeman et al., 1977) and only seven isolates representing six strains could not be identified; three strains were non-pigmented non-saccharolytic species and two were members of the $B$. fragilis group that could not be assigned to one of the nine recognised species. However, 55 B. fragilis-group isolates $(33 \%)$ gave atypical results in isolated tests; most atypical results were in tolerance tests with taurocholate, Victoria blue 4R or ethyl violet, or in antibiotic-disk resistance tests with neomycin or penicillin. These results did not cause any difficulties in the identification of strains but they emphasise the importance of using the tests as a set so that the individual aberrant results are recognised and do not lead to errors in identification.

The present investigations have shown that the gram-negative anaerobic bacilli from faeces can be isolated and identified by conventional bacteriological methods. Species of the $B$. fragilis group were predominant in the normal faecal flora and a variety of species were identified. B. vulgatus and $B$. thetaiotaomicron were the commonest species and $B$. fragilis was not a major component of the normal flora.

\section{SUMMARY}

Gram-negative anaerobic bacilli of the Bacteroides group were isolated on an enriched selective medium from specimens of faeces from 20 normal healthy adults and identified by conventional bacteriological methods. A heavy growth of Bacteroides spp. was obtained from all specimens and 10 representative colonies from each subject were identified. Most isolates $(84 \%)$ belonged to the $B$. fragilis group. The commonest species identified in this group were $B$. vulgatus and $B$. thetaiotaomicron $(22 \%$ each), B. distasonis $(18 \%)$ and the $B$. eggerthii/variabilis complex $(14 \%)$, and only $9 \%$ were $B$. fragilis. $B$. vulgatus was isolated from $80 \%$ of subjects, $B$. thetaiotaomicron and $B$. distasonis from $70 \%$ each and the B. eggerthii/variabilis complex from $65 \%$, but $B$. fragilis was detected in only $45 \%$ of specimens. Asaccharolytic species were isolated in smaller numbers from $14(70 \%)$ subjects, but only five strains of the $B$. melaninogenicus/oralis group were isolated and fusobacteria were not detected.

I am grateful to Professor J. G. Collee for encouragement and advice throughout these investigations and to Mrs Julia Faulkner for her invaluable technical assistance.

\section{REFERENCES}

Aranki, A. AND Freter, R. 1972. Use of anaerobic glove boxes for the cultivation of strictly anaerobic bacteria. Amer. J. clin. Nut., 25, 1329.

Aranki, A., Syed, S. A., KenNEY, E. B. AND FRETER, R. 1969. Isolation of anaerobic bacteria from human gingiva and mouse caecum by means of a simplified glove box procedure. Appl. Microbiol., 17, 568. 
Cato, E. P. And Johnson, J. L. 1976. Reinstatement of species rank for Bacteroides fragilis, $B$. ovatus, $B$. distasonis, $B$. thetaiotaomicron, and B. vulgatus. Designation of neotype strains for Bacteroides fragilis (Veillon and Zuber) Castellani and Chalmers and Bacteroides thetaiotaomicron (Distaso) Castellani and Chalmers. Int. J. syst. Bact., 26, 230.

Collee, J. G., Watt, B., Fowler, E. B. and Brown, R. 1972. An evaluation of the Gaspak system in the culture of anaerobic bacteria. J. appl. Bact., 35, 71.

Deacon, A. G., Duerden, B. I. ANd Holbrook, W. P. 1978. Gas-liquid chromatographic analysis of metabolic products in the identification of Bacteroidaceae of clinical interest. $J$. med. Microbiol., 11, 81.

Drasar, B. S. 1967. Cultivation of anaerobic intestinal bacteria. J. Path. Bact., 94, 417.

DraSAR, B. S. 1974. Some factors associated with geographical variations in the intestinal microflora, In The normal microbial flora of man, edited by F. A. Skinner and J. G. Carr, Society for Applied Bacteriology, symposium series 3. Academic Press; London, p. 187.

DUERDEN, B. I. 1980a. The isolation and identification of Bacteroides spp. from the normal human vaginal flora. J. med. Microbiol., 13, 79.

DUERDEN, B. I. 1980b. The isolation and identification of Bacteroides spp. from the normal human gingival flora. J. med. Microbiol.. 13,89.

Duerden, B. I., Collee, J. G., Brown, R., Deacon, A. G. and Holbrook, W. P. 1980. A scheme for the identification of clinical isolates of gram-negative anaerobic bacilli by conventional bacteriological tests. J. med. Microbiol., 13, in press.

Duerden, B. I., Holbrook, W. P., Collee, J. G. And Watt, B. 1976. The characterization of clinically important gram-negative anaerobic bacilli by conventional bacteriological tests. J. appl. Bact., 40, 163.

Finegold, S. M. 1977. Anaerobic bacteria in human disease. Academic Press: London.

Finegold, S. M., Attebury, H. R. And Sutter, V. L. 1974. Effect of diet on human faecal flora: comparison of Japanese and American diets. Amer. J. clin. Nutr., 27, 1456.

FineGold, S. M. ANd Barnes, E. M. 1977. Report of the ICSB Taxonomic Subcommittee on gram-negative anaerobic rods. Int. J. syst. Bact., 27, 388.

Finegold, S. M., Flora, D. J., Attebury, H. R. and Sutter, V. L. 1975. Fecal bacteriology of colonic polyp patients and control patients. Cancer Res., 35, 3407.

Finegold, S. M., Sugihara, P. T. And Sutter, V. L. 1971. Use of selective media for isolation of anaerobes from humans, In Isolation of anaerobes, edited by D. S. Shapton and R. G. Board. Academic Press: London, p. 99.

Hill, M. J., Drasar, B. S., Aries, V., Crowther, J. S., Hawksworth, G. and Williams, R. E. O. 1971. Bacteria and aetiology of cancer of large bowel. Lancet, 1, 95.

Holbrook, W. P., Ogston, S. A. And Ross, P. W. 1978. A method for the isolation of Bacteroides melaninogenicus from the human mouth. J. med. Microbiol., 11, 203.

Holdeman, L. V., Cato, E. P. And Moore, W. E. C. 1977. Anaerobe Laboratory Manual, 2nd ed. Virginia Polytechnic Institute and State University: Blacksburg.

Holdeman, L. V. And Moore, W. E. C. 1974a. Bacteroidaceae, In Bergey's Manual of determinative bacteriology, 8th ed., edited by R. E. Buchanan and N. E. Gibbons. Williams \& Wilkins: Baltimore, p. 384.

Holdeman, L. V. and Moore, W. E. C. 1974b. New genus, Coprococcus, twelve new species, and emended descriptions of four previously described species of bacteria from human faeces. Int. J. syst. Bact., 24, 260.

Holland, J. W., Hill, E. O. AND Altemeier, W. A. 1977. Numbers and types of anaerobic bacteria isolated from clinical specimens since 1960. J. clin. Microbiol., 5, 20.

Hungate, R. E. 1950. The anaerobic mesophilic cellulolytic bacteria. Bact. Rev., 14, 1.

LOESChe, W. J., HocketT, R. N. AND SYed, S. A. 1972. The predominant cultivable flora of tooth surface plaque removed from institutionalised subjects. Arch. oral Biol., 17, 1311.

MöLLER, A. J. R. 1966. Microbiological examinations of root canals and periapical tissues of human teeth: methodological studies. Odont. Tid., 74, (suppl.), p. 365.

Moore, W. E. C. and Holdeman, L. V. 1975. Some newer concepts of the human intestinal flora. Amer. J. med. Technol., 41, 427.

Rosenblatt, J. E., Fallon, A. ANd Finegold, S. M. 1973. Comparison of methods for 
isolation of anaerobic bacteria from clinical specimens. Appl. Microbiol., 25, 77.

STARR, S. E. 1974. Comparison of isolation techniques for anaerobic bacteria, In Anaerobic bacteria: role in disease, edited by A. Balows, R. M. de Haan, V. R. Dowell, JR and L. B. Guze. Thomas: Springfield, p. 47.

Watt, B., ColleE, J. G. AND BRown, R. 1974. The isolation of strict anaerobes: the use of an anaerobic cabinet compared with a conventional procedure. J. med. Microbiol., 7, 315.

WERNER, H. 1974. Differentiation and medical importance of saccharolytic intestinal Bacteroides. Arzneimittel-Forsch. (Drug Res.), 24, 340.

Werner, H. ANd Pulverer, G. 1971. Haufigkeit und medizinische Bedeutung der eitererregenden Bacteroides-und Sphaerophorus-Arten. Dt. med. Wschr., 96, 1325.

Werner, H., Pulverer, G. And Reichertz, C. 1971. The biochemical properties and antibiotic susceptibility of Bacteroides melaninogenicus. Med. Microbiol. Immunol. (Berl)., 157,3 .

WerneR, H., Rintelen, G. AND Kunstek-Santos, H. 1975. A new butyric acid-producing Bacteroides species: B. splanchnicus n. sp. Zentbl. Bakt. Parasit Kde, I Abt. Orig., 231, 133.

Williams, R. A. D., Bowden, G. H., Hardie, J. M. and Shah, H. 1975. Biochemical properties of Bacteroides melaninogenicus subspecies. Int. J. syst. Bact., 25, 298. 